\title{
Effect of an Educational Support Programme on Caregiver Burden Among the Family Members of Patients Undergoing Coronary Artery Bypass Graft Surgery
}

Helen Dalirirad, "Tahereh Najafi, Naima Seyedfatemi

ABSTRACT: Objectives: The family caregivers of patients undergoing coronary artery bypass graft (CABG) surgery experience considerable physical and emotional distress. This study aimed to investigate the effect of an educational support programme on caregiver burden among the family caregivers of patients undergoing CABG surgery in Iran. Methods: This non-randomised controlled clinical trial was conducted from January to April 2017 at a cardiovascular centre in Tehran, Iran. A total of 80 family caregivers of patients undergoing CABG surgery were sequentially selected and non-randomly assigned to intervention and control groups. The control group received routine care, whereas the intervention group received additional education sessions at baseline, prior to surgery, the day after surgery and before discharge. Caregiver burden was compared at baseline and six weeks post-discharge using the Persian-language versions of the Caregiver Burden Inventory (CBI) and Katz Index of Independence in Activities of Daily Living (IADL). Results: A significant difference was observed between family caregivers in the control and intervention groups with regards to pre-post differences in mean CBI scores $(+1.67 \pm 19.23$ versus $+17.45 \pm 9.83 ; P<0.001)$, with an effect size of -1.14 . In addition, there was a significant increase in mean post-discharge IADL scores among CABG patients in the intervention group compared to the control group (4.42 \pm 1.05 versus $3.07 \pm 1.09 ; P<0.001)$. Conclusion: An educational support programme significantly reduced caregiver burden among the family members of patients undergoing CABG surgery in Iran. As such, in addition to routine care, healthcare providers should provide educational support to this population to help mitigate caregiver burden.

Keywords: Caregiver Burden; Coronary Artery Bypass Surgery; Patient Education as Topic; Caregivers; Education; Quality of Life; Controlled Clinical Trial; Iran.

\section{ADVANCES IN KNOWLEDGE}

An educational programme was found to be effective in reducing caregiver burden among the family caregivers of patients undergoing coronary artery bypass graft surgery in Iran.

Application to Patient Care

Healthcare providers should seek to decrease caregiver burden using appropriate educational programmes, such as the one described in this study.

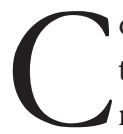
ONARY HEART DISEASE IS THE ONE OF the greatest causes of death worldwide, resulting in approximately 17.5 million deaths annually, of which $80 \%$ occur in low- and middleincome countries. ${ }^{1}$ Coronary artery bypass graft (CABG) surgery is a potentially lifesaving treatment for heart disease; however, it can have debilitating physical and mental consequences. ${ }^{2,3}$ As such, patients often require a considerable degree of care before, during and immediately after surgery as well as during their lengthy recovery period. However, due to advancements in technology and recent changes in the healthcare system which have shortened the duration of hospital stay, patients with long-term and complex care needs are often taken care of at home by their family members. ${ }^{4}$ In addition, limitations in home care services have increased familial responsibility for providing patient care. ${ }^{5}$
Family caregivers provide care to patients with chronic illnesses over multiple dimensions, including emotional and financial support during periods of hospitalisation, along with physical and organisational tasks related to managing postoperative pain, wound care, the administration of medications and changes in diet and lifestyle. ${ }^{6}$ These tasks result in increased stress on the part of the caregiver, potentially threatening their health and giving rise to chronic illnesses. ${ }^{7.8}$ Many family caregivers report not feeling prepared for the burden and demands of caregiving for patients undergoing CABG surgery.,

Although the majority of caregiving for patients undergoing CABG surgery usually falls on family members, most studies focus primarily on the needs of the patients, with few studies evaluating the burden on family caregivers, particularly in the Middle East. ${ }^{10,11} \mathrm{~A}$ previous qualitative study explored caregiver burden 
among the family members of patients with heart failure in Iran; the researchers identified four themes including lack of care-related knowledge, physical exhaustion, psychosocial exhaustion and lack of support, and emphasised the necessity of providing more effective social, informational and professional support to family caregivers. ${ }^{12}$ As such, this study aimed to investigate the effect of an educational support programme on caregiver burden among the family caregivers of patients undergoing CABG surgery in an urban area of Iran.

\section{Methods}

This non-randomised controlled clinical trial was conducted from January to April 2017 at a cardiovascular centre in Tehran, Iran. This 601-bed centre is one of the largest specialist and subspecialist heart centres in Iran. Family caregivers of patients undergoing CABG surgery at this centre were selected using a sequential sampling method. The inclusion criteria consisted of family members who had taken on the main role in providing care to the patient for at least two months and who could read, write and communicate in Persian. ${ }^{10}$ Individuals with physical and psychosomatic illnesses and those with a previous history of cardiac surgery or of caring for a patient undergoing cardiac surgery were excluded, as were those concurrently providing care to another person with physical or mental illness or employed as healthcare professionals.

The necessary sample size was calculated to be 40 patients in each group based on a $95 \%$ confidence interval (CI) and type II error of 0.2, assuming an effect size of 3 of the intervention on caregiver burden, a $10 \%$ drop-out rate and a standard deviation of 14.3 and 12.0 in the intervention and control groups, respectively. ${ }^{10}$ Due to the possibility of contamination, sampling for the intervention group was conducted prior to sampling for the control group. In both instances, sampling was continued until the desired sample size was reached. Due to the nature of the intervention, blinding of the research subjects was impossible.

Caregivers in the control group received only routine care including standard postoperative care education provided by a nurse and education pamphlets on the day of discharge from the hospital. In addition to routine care, caregivers in the intervention group underwent four educational sessions lasting 45-60 minutes. These sessions were conducted either in the staff room or the caregivers' waiting room at four different time points: baseline (i.e. the beginning of the study), before the surgery, the day after the surgery and before discharge from the hospital. Caregivers were taught by one of the researchers using various approaches including face-to-face learning, video tutorials, skill demonstrations and interactive discussions. In addition, the caregivers received educational materials in the form of a pamphlet and compact computer disc for perusal at home. At the beginning of each session, the educational content of the previous session were reviewed in terms of changes to the patients' condition. Further details of the educational programme are presented in Table 1.

Subsequently, after the patients had been discharged from hospital, caregivers in the intervention group were contacted by telephone calls on a weekly basis to exchange information and provide support tailored to the subjects' needs. This method of follow-up was employed since it is often used in clinical practice to support patients after discharge and is an easily accessible mode of communication. The telephone conversations included questions about the patient's and caregiver's physical, psychosocial and social health status, educational content, discussions and the provision of solutions to any problems. At the end of each call, an appointment was made to schedule the time and date of the next call. Caregivers were also informed that they could contact the researcher in the meantime if they had any questions or faced any problems. Conversations varied in length with an average duration of 10 minutes. The researcher also provided digital educational materials to the caregivers via a mobile social networking application.

Data were collected from the participants using a demographic data form, as well as the Caregiver Burden Inventory (CBI) and the Katz Index of Independence in Activities of Daily Living (IADL). ${ }^{13,14}$ The demographic data form was developed and completed by the researchers during interviews with the subjects upon entering the study, in conjunction with a review of the patients' health records. A Persian version of the 24-item CBI tool was used to measure five dimensions of caregiver burden including time dependence (five items), evolution (five items), physical burden (four items), social burden (five items) and emotional burden (five items). ${ }^{13,15}$ Responses to each item were measured on a 5-point Likert scale in terms of frequency from 0 (never) to 4 (always). Total scores ranged from $0-96$, with scores of $>36$ indicative of a high burden on the caregiver. ${ }^{13}$ All of the individual dimension subscales had total scores ranging from 0-20, expect the third one, which had a total score ranging from $0-16$. A previous study reported that the Iranian version of the CBI was valid and reliable (Cronbach's alpha coefficient: 0.90). ${ }^{15}$ The version of 
the tool used in the current study was also found to have appropriate internal consistency (Cronbach's alpha coefficient: 0.946).

A Persian version of the six-item IADL was used to measure the functional status of the patients. ${ }^{14,16}$ This tool includes six questions regarding the individual' ability to perform everyday activities including going to the bathroom, going to bed, eating, dressing, controlling their bladder/bowels and moving around. Each item was scored out of 2, with a score of 1 indicating the patient's independence in performing the task and a score of 0 indicating dependence on others. Total scores ranged from 0-6, with scores of $<3,3-4$ and 5-6 indicative of severe functional disability, moderate functional disability and complete independence, respectively. ${ }^{14}$ The Iranian version of the tool has been found to be valid and reliable (Cronbach's alpha coefficient: 0.923). ${ }^{16}$ In the current study, the tool similarly had high internal consistency (Cronbach's alpha coefficient: 0.950). Participants in both groups initially completed the CBI and IADL sections of the questionnaire at baseline, upon entering the study, and for a second time six weeks after discharge from the hospital. This follow-up duration was determined because CABG patients usually require up to a sixweek recovery period before being able to resume their normal daily activities. ${ }^{17}$

Data were analysed using the Statistical Package for the Social Sciences (SPSS), Version 13.0 (IBM Corp., Armonk, New York, USA). A KolmogorovSmirnov test was used to examine the normality of the distribution of the variables. Comparisons between the groups were performed using an independent t-test, Chi-squared test or Fisher's exact test, as appropriate. Effect size was evaluated using Cohen's d method. A $P$ value of $<0.050$ was considered statistically significant. A lack of participation of the subjects in one education session and patient/caregiver death were considered per-protocol analysis criteria resulting in exclusion of subjects from the study.

Permission to conduct this trial was granted by the Ethics Committee of the Iran University of Medical Sciences (IR.IUMS.REC1395.9313677002). The research protocol was also registered with the Iranian Registry of Clinical Trials (IRCT \#2016030526900N1). Written informed consent was obtained from all subjects and patients prior to participation in the trial. All data were kept confidential and unique study identifiers were used to assure anonymity. Collected data were kept in a locked file to which only the primary investigator had access. After completion of the study, all educational materials from the programme were also supplied to individuals in the control group.

\section{Results}

A total of 80 family caregivers took part in the study, with no participants lost to follow-up or attrition. Caregivers in the control and intervention groups were homogeneous in terms of all demographic characteristics, except for gender and previous experience receiving educational sessions [Table 2]. However, an independent $\mathrm{t}$-test confirmed that gender and previous education experience were not confounding variables. In addition, no significant differences were reported between the groups in terms of patient characteristics [Table 3].

Table 1: Details of an educational support intervention for the family caregivers of patients undergoing coronary artery bypass graft surgery

\begin{tabular}{|c|c|c|c|}
\hline $\begin{array}{l}\text { Time of } \\
\text { session }\end{array}$ & $\begin{array}{l}\text { Content of } \\
\text { session }\end{array}$ & $\begin{array}{l}\text { Educational } \\
\text { approach }\end{array}$ & $\begin{array}{l}\text { Duration of } \\
\text { session in } \\
\text { minutes }\end{array}$ \\
\hline \multirow[t]{3}{*}{ Baseline } & $\begin{array}{l}\text { - Awareness } \\
\text { of the hospital } \\
\text { and different } \\
\text { wards (i.e. } \\
\text { open-heart } \\
\text { care, post- } \\
\text { surgery care, } \\
\text { etc.) }\end{array}$ & 10 & \multirow[t]{3}{*}{$\begin{array}{l}\text { - Face-to-face } \\
\text { - Skill } \\
\text { demonstration } \\
\text { - Question and } \\
\text { answer } \\
\text { - Pamphlet }\end{array}$} \\
\hline & $\begin{array}{l}\text { - Anxiety and } \\
\text { stress }\end{array}$ & 15 & \\
\hline & $\begin{array}{l}\text { - Coping skills } \\
\text { and stress } \\
\text { management }\end{array}$ & 35 & \\
\hline \multirow[t]{2}{*}{$\begin{array}{l}\text { Before } \\
\text { the } \\
\text { surgery }\end{array}$} & $\begin{array}{l}\text { - Heart } \\
\text { diseases and } \\
\text { the CABG } \\
\text { surgery }\end{array}$ & 30 & \multirow{2}{*}{$\begin{array}{l}\text { - Face-to-face } \\
\text { - Question and } \\
\text { answer } \\
\text { - Video clips } \\
\text { - Pamphlet }\end{array}$} \\
\hline & $\begin{array}{l}\text { - Immediate } \\
\text { postoperative } \\
\text { care }\end{array}$ & 15 & \\
\hline \multirow[t]{3}{*}{$\begin{array}{l}\text { Day } \\
\text { after the } \\
\text { surgery }\end{array}$} & $\begin{array}{l}\text { - Medical } \\
\text { condition and } \\
\text { patient care } \\
\text { after surgery }\end{array}$ & 45 & \multirow{3}{*}{$\begin{array}{l}\text { - Face-to-face } \\
\text { - Question and } \\
\text { answer } \\
\text { - Video clips } \\
\text { - Skill } \\
\text { demonstration }\end{array}$} \\
\hline & $\begin{array}{l}\text { - Lung } \\
\text { physiotherapy } \\
\text { - Wound care }\end{array}$ & & \\
\hline & $\begin{array}{l}\text { - Diet and } \\
\text { medication }\end{array}$ & & \\
\hline \multirow{4}{*}{$\begin{array}{l}\text { Before } \\
\text { discharge } \\
\text { from the } \\
\text { hospital }\end{array}$} & $\begin{array}{l}\text { - Home care } \\
\text { - Diet and }\end{array}$ & 30 & \multirow{4}{*}{$\begin{array}{l}\text { - Question and } \\
\text { answer } \\
\text { - Demonstration } \\
\text { of skills } \\
\text { - Video clips } \\
\text { - Compact } \\
\text { computer disc }\end{array}$} \\
\hline & medication & & \\
\hline & $\begin{array}{l}\text { - Wound care } \\
\text { - Prevention } \\
\text { of infection } \\
\text { after surgery }\end{array}$ & & \\
\hline & $\begin{array}{l}\text { - Readmission } \\
\text { for follow- } \\
\text { up visits } \\
\text { - Cardiac } \\
\text { rehabilitation } \\
\text { - Surgical } \\
\text { complications } \\
\text { - Postoperative } \\
\text { activities }\end{array}$ & 30 & \\
\hline
\end{tabular}

$C A B G=$ coronary artery bypass graft. 
Table 2: Demographic characteristics according to group allocation* of family caregivers of patients undergoing coronary artery bypass graft surgery at a specialist heart centre in Tehran, Iran $(\mathrm{N}=80)$

\begin{tabular}{|c|c|c|c|}
\hline \multirow[t]{2}{*}{ Characteristic } & \multicolumn{2}{|c|}{ n (\%) } & \multirow{2}{*}{$\begin{array}{c}P \\
\text { value }\end{array}$} \\
\hline & $\begin{array}{l}\text { Intervention } \\
\text { group } \\
(\mathrm{n}=40)\end{array}$ & $\begin{array}{l}\text { Control } \\
\text { group } \\
(n=40)\end{array}$ & \\
\hline \multicolumn{3}{|l|}{ Age in years } & 0.428 \\
\hline Mean \pm SD & $39.20 \pm 10.41$ & $41.05 \pm 10.35$ & \\
\hline \multicolumn{3}{|l|}{ Gender } & $0.002^{\dagger}$ \\
\hline Male & $10(25)$ & $24(60)$ & \\
\hline Female & $30(75)$ & $16(40)$ & \\
\hline \multicolumn{3}{|l|}{ Marital status } & 0.363 \\
\hline Married & $35(87.5)$ & $8(50)$ & \\
\hline Single & $5(12.5)$ & $32(80.0)$ & \\
\hline \multicolumn{3}{|c|}{ Employment status } & 0.551 \\
\hline Unemployed & $1(2.5)$ & $3(7.5)$ & \\
\hline Employed & $13(32.5)$ & $15(37.5)$ & \\
\hline Housewife & $19(47.5)$ & $12(30)$ & \\
\hline Self-employed & $5(12.5)$ & $9(22.5)$ & \\
\hline Retired & $2(5)$ & $1(2.5)$ & \\
\hline \multicolumn{3}{|l|}{ Education level } & 0.560 \\
\hline Primary & $4(10)$ & $5(12.5)$ & \\
\hline Secondary & $7(17.5)$ & $5(12.5)$ & \\
\hline Diploma & $13(32.5)$ & $18(45)$ & \\
\hline University & $16(40)$ & $12(30)$ & \\
\hline \multicolumn{3}{|c|}{ Self-reported income } & 0.500 \\
\hline Sufficient & $18(45)$ & $23(57.5)$ & \\
\hline $\begin{array}{l}\text { Somewhat } \\
\text { sufficient }\end{array}$ & $20(50)$ & $16(40)$ & \\
\hline Insufficient & $2(5)$ & $1(2.5)$ & \\
\hline \multicolumn{3}{|c|}{ Person responsible for medical expenses } & 0.459 \\
\hline Patient & $27(67.5)$ & $30(75)$ & \\
\hline Caregiver & $13(32.5)$ & $10(25)$ & \\
\hline $\begin{array}{l}\text { Number } \\
\text { of children } \\
\text { among married } \\
\text { participants }\end{array}$ & $(\mathbf{n}=35)$ & $(\mathrm{n}=32)$ & 0.569 \\
\hline 0 & $4(11.4)$ & $1(3.1)$ & \\
\hline 1 & $6(17.1)$ & $7(21.9)$ & \\
\hline 2 & $16(45.7)$ & $16(50)$ & \\
\hline 3 & $5(14.3)$ & $4(12.5)$ & \\
\hline 4 & $1(2.9)$ & $4(12.5)$ & \\
\hline$>4$ & $3(8.6)$ & $0(0)$ & \\
\hline
\end{tabular}

\begin{tabular}{|c|c|c|c|}
\hline \multicolumn{4}{|c|}{ History of illness ${ }^{\ddagger}$} \\
\hline Heart failure & $7(17.5)$ & $1(2.5)$ & 0.057 \\
\hline Hyperlipidaemia & $6(15)$ & $7(17.5)$ & 0.762 \\
\hline Diabetes & $1(2.5)$ & $6(15)$ & 0.108 \\
\hline \multicolumn{3}{|c|}{$\begin{array}{l}\text { Previous experience receiving educational } \\
\text { sessions }\end{array}$} & 0.040 \\
\hline Yes & $4(10)$ & $0(0)$ & \\
\hline No & $36(90)$ & $40(100)$ & \\
\hline
\end{tabular}

Primary source of information about surgery $\quad 0.417$

$\begin{array}{lll}\text { None } & 20(50) & 15(37.5)\end{array}$

Healthcare $\quad 5(12.5) \quad 7(17.5)$

personnel

Personal
research

Media $\quad 4(10) \quad 0(0)$

Internet $\quad 7(17.5) \quad 6(15)$

Relatives $\quad 0(0) \quad 7(17.5)$

$S D=$ standard deviation

"The control group received normal care, whereas the intervention group received additional education sessions at baseline, prior to surgery, the day after surgery and before discharge. ${ }^{\top}$ Statistically significant at $P<0.050$. ${ }^{*}$ Percentages for this variable do not add up to $100 \%$ as some subjects may have had more than one illness or none.

At baseline, patients in both groups were completely independent. However, fewer patients in the control group were completely independent six weeks after discharge compared to those in the intervention group (12.5\% versus 45\%). Nevertheless, the majority of patients in both groups were relatively independent (60\% and 50\%, respectively) [Table 4]. There was a statistically significant difference with regards to mean IADL scores six weeks post-discharge $(3.07 \pm 1.09$ versus $4.42 \pm 1.05 ; \mathrm{t}=5.60$; degrees of freedom $=78 ; P<0.001)$. At baseline, most caregivers reported a low level of caregiver burden, regardless of allocation to the control or intervention groups (75\% and $60 \%$, respectively). Six weeks after discharge, the majority $(80 \%)$ of subjects in the intervention group reported a low burden, whereas most caregivers (72.5\%) in the control group reported a high burden [Table 5].

Table 6 presents a comparison of mean CBI scores for specific dimensions of caregiver burden at baseline and six weeks post-discharge in both groups. No significant difference was observed in mean CBI scores between the intervention and control groups at baseline ( $31.87 \pm 21.45$ versus $25.67 \pm 14.97 ; P=0.138$ ) However, there was a statistically significant difference in mean scores post-discharge (33.55 \pm 5.54 versus $43.12 \pm 10.51 ; P<0.001)$. While the difference in prepost mean $\mathrm{CBI}$ scores increased from baseline in 
Table 3: Demographic characteristics according to group allocation* of patients undergoing coronary artery bypass graft surgery at a specialist heart centre in Tehran, Iran $(\mathrm{N}=80)$

\begin{tabular}{|c|c|c|c|}
\hline \multirow[t]{2}{*}{ Characteristic } & \multicolumn{2}{|c|}{ n (\%) } & \multirow[t]{2}{*}{$P$ value } \\
\hline & $\begin{array}{l}\text { Intervention } \\
\text { group } \\
(\mathrm{n}=40)\end{array}$ & $\begin{array}{l}\text { Control } \\
\text { group } \\
(n=40)\end{array}$ & \\
\hline \multicolumn{4}{|l|}{ Age in years } \\
\hline Mean \pm SD & $57.12 \pm 9.64$ & $58.15 \pm 9.45$ & 0.633 \\
\hline Gender & & & 0.459 \\
\hline Male & $30(75)$ & $13(67.5)$ & \\
\hline Female & $10(25)$ & $27(32.5)$ & \\
\hline \multicolumn{3}{|l|}{ Education level } & 0.817 \\
\hline Illiterate & $4(10)$ & $3(7.5)$ & \\
\hline Primary & $14(35)$ & $15(37.5)$ & \\
\hline Secondary & $8(20)$ & $6(15)$ & \\
\hline Diploma & $9(22.5)$ & $13(32.5)$ & \\
\hline University & $5(12.5)$ & $3(7.5)$ & \\
\hline \multicolumn{3}{|l|}{ Living status } & 0.326 \\
\hline Alone & $2(5)$ & $1(2.5)$ & \\
\hline $\begin{array}{l}\text { With children } \\
\text { and spouse }\end{array}$ & $35(87.5)$ & $38(95)$ & \\
\hline With children & $3(7.5)$ & $0(0)$ & \\
\hline With parents & $0(0)$ & $1(2.5)$ & \\
\hline \multicolumn{3}{|c|}{ Time from diagnosis to surgery in weeks } & 0.313 \\
\hline$>2$ & $10(25)$ & $6(15)$ & \\
\hline $3-8$ & $11(27.5)$ & $19(47.5)$ & \\
\hline $9-12$ & $5(12.5)$ & $2(5)$ & \\
\hline $13-24$ & $9(22.5)$ & $7(17.5)$ & \\
\hline$\geq 25$ & $5(12.5)$ & $6(15)$ & \\
\hline \multicolumn{4}{|l|}{ History of illness ${ }^{\dagger}$} \\
\hline Kidney failure & $3(7.5)$ & $2(5)$ & 0.990 \\
\hline $\begin{array}{l}\text { High blood } \\
\text { pressure }\end{array}$ & $20(50)$ & $24(60)$ & 0.369 \\
\hline Hyperlipidaemia & $21(52.5)$ & $14(35)$ & 0.115 \\
\hline Diabetes & $17(42.5)$ & $18(45)$ & 0.822 \\
\hline \multicolumn{3}{|c|}{ Number of coronary arteries involved } & 0.833 \\
\hline 1 & $2(5)$ & $1(2.5)$ & \\
\hline 2 & $7(17.5)$ & $9(22.5)$ & \\
\hline$\geq 3$ & $31(77.5)$ & $30(75)$ & \\
\hline
\end{tabular}

$S D=$ standard deviation

The control group received normal care, whereas the intervention group received additional education sessions at baseline, prior to surgery, the day after surgery and before discharge. ${ }^{\dagger}$ Percentages for this variable do not add up to $100 \%$ as some subjects may have had more than one illness or none.
Table 4: Ability to perform activities of daily living* six weeks after discharge according to group allocation ${ }^{\dagger}$ among patients who had received coronary artery bypass graft surgery at a specialist heart centre in Tehran, Iran $(\mathrm{N}=80)$

\begin{tabular}{lcc}
$\begin{array}{l}\text { Level of } \\
\text { independence }\end{array}$ & \multicolumn{2}{c}{$\mathbf{n}(\%)$} \\
& $\begin{array}{c}\text { Intervention group } \\
(\mathrm{n}=40)\end{array}$ & $\begin{array}{c}\text { Control group } \\
(\mathrm{n}=40)\end{array}$ \\
$\begin{array}{l}\text { Dependent } \\
\begin{array}{l}\text { Relatively } \\
\text { independent }\end{array}\end{array}$ & $2(5)$ & $11(27.5)$ \\
$\begin{array}{l}\text { Completely } \\
\text { independent }\end{array}$ & $18(45)$ & $24(60)$ \\
\end{tabular}

"Self-assessed using a Persian version of the 6-item Katz Index of Independence in Activities of Daily Living Index. ${ }^{14,16}{ }^{+}$The control group received normal care, whereas the intervention group received additional education sessions at baseline, prior to surgery, the day after surgery and before discharge. ${ }^{\neq}$Total sum scores ranged from $0-6$, with scores of $<3,3-4$ and 5-6 indicative of severe functional disability, moderate functional disability and complete independence, respectively. ${ }^{14}$

Table 5: Changes in caregiver burden* at baseline and six weeks post-discharge according to group allocation ${ }^{\dagger}$ among family caregivers of patients undergoing coronary artery bypass graft surgery at a specialist heart centre in Tehran, Iran $(\mathrm{N}=80)$

\begin{tabular}{lcccc}
$\begin{array}{c}\text { Level of } \\
\text { burden }^{\ddagger}\end{array}$ & $\begin{array}{c}\text { n (\%) } \\
\text { Intervention group } \\
(\mathbf{n}=40)\end{array}$ & \multicolumn{2}{c}{$\begin{array}{c}\text { Control group } \\
(\mathbf{n}=40)\end{array}$} \\
& Baseline & $\begin{array}{c}\text { After 6 } \\
\text { weeks }\end{array}$ & Baseline & $\begin{array}{c}\text { After 6 } \\
\text { weeks }\end{array}$ \\
Low & $24(60)$ & $32(80)$ & $30(75)$ & $\begin{array}{c}11 \\
(27.5)\end{array}$ \\
High & $16(40)$ & $8(20)$ & $10(25)$ & 29 \\
& & & & $(72.5)$
\end{tabular}

*Self-assessed using a Persian version of the 24-item Caregiver Burden Index tool..$^{13,15}{ }^{+}$The control group received normal care, whereas the intervention group received additional education sessions at baseline, prior to surgery, the day after surgery and before discharge. ${ }^{*}$ Total sum scores ranged from 0-96, with scores of $\leq 35$ and $>36$ indicative of a low or high level of burden, respectively. ${ }^{13}$

both the intervention and control groups, there was a significantly smaller increase in the intervention compared to the control group $(+1.67 \pm 19.23$ versus $+17.45 \pm 9.83 ; P<0.001)$. The effect size of the educational programme in reducing caregiver burden was high (effect size: -1.14 ; 95\% CI: -1.61 to 0.67 ).

With regards to specific dimensions of caregiver burden, there was a significant difference at baseline between the intervention and control groups in terms of mean CBI scores for the time dependence subscale $(9.72 \pm 5.30$ versus $5.17 \pm 4.14 ; P<0.001)$. No differences were noted between the groups at baseline for the other dimensions of the CBI tool. However, six weeks after discharge, significant differences in mean CBI scores were noted between the groups in terms of time dependence $(7.47 \pm 2.40$ versus $11.22 \pm 2.73$; $P<0.001)$, physical burden $(6.55 \pm 1.69$ versus $8.15 \pm 2.41$; $P=0.007)$, social burden ( $6.37 \pm 1.84$ versus $5.62 \pm 3.09$; 
Table 6: Changes in specific dimensions of caregiver burden* at baseline and six weeks post-discharge according to group allocation + among family caregivers of patients undergoing coronary artery bypass graft surgery at a specialist heart centre in Tehran, Iran $(\mathrm{N}=80)$

\begin{tabular}{|c|c|c|c|c|c|}
\hline \multirow[t]{2}{*}{ Dimension } & \multicolumn{2}{|c|}{ Mean sum CBI score ${ }^{\ddagger} \pm \mathrm{SD}$} & \multirow[t]{2}{*}{ t value ${ }^{\mathbb{S}}$} & \multirow[t]{2}{*}{$P$ value } & \multirow[t]{2}{*}{ Effect size (95\% CI) } \\
\hline & $\begin{array}{l}\text { Intervention group } \\
\qquad(\mathrm{n}=40)\end{array}$ & $\begin{array}{l}\text { Control group } \\
(\mathbf{n}=40)\end{array}$ & & & \\
\hline \multicolumn{6}{|c|}{ Time dependence } \\
\hline Baseline & $9.72 \pm 5.30$ & $5.17 \pm 4.14$ & 4.27 & $<0.001$ & - \\
\hline After 6 weeks & $7.47 \pm 2.40$ & $11.22 \pm 2.73$ & -6.51 & $<0.001$ & $-1.45(-1.95$ to -0.96$)$ \\
\hline Change & $-2.25 \pm 4.43$ & $+6.05 \pm 3.62$ & -9.16 & $<0.001$ & $-2.05(-2.59$ to -1.51$)$ \\
\hline \multicolumn{6}{|l|}{ Evolution } \\
\hline Baseline & $6.10 \pm 6.05$ & $4.67 \pm 3.30$ & 1.30 & 0.195 & - \\
\hline After 6 weeks & $6.80 \pm 1.91$ & $7.80 \pm 2.98$ & -1.78 & 0.199 & -0.39 ( -0.84 to 0.04$)$ \\
\hline Change & $+0.70 \pm 6.06$ & $+3.12 \pm 2.31$ & -2.36 & $0.021^{\prime}$ & $-0.52(-0.97$ to -0.08$)$ \\
\hline \multicolumn{6}{|l|}{ Physical burden } \\
\hline Baseline & $5.72 \pm 4.91$ & $5.47 \pm 2.90$ & 0.27 & 0.783 & - \\
\hline After 6 weeks & $6.55 \pm 1.69$ & $8.15 \pm 2.41$ & -3.43 & $0.007^{9}$ & $-0.76(-1.22$ to -0.31$)$ \\
\hline Change & $+0.82 \pm 4.09$ & $+2.67 \pm 2.86$ & -2.34 & $0.022^{9}$ & $-0.52(-0.97$ to -0.07$)$ \\
\hline \multicolumn{6}{|l|}{ Social burden } \\
\hline Baseline & $4.22 \pm 4.85$ & $3.80 \pm 3.13$ & 0.46 & 0.643 & - \\
\hline After 6 weeks & $6.37 \pm 1.84$ & $5.62 \pm 3.09$ & 1.31 & $0.003^{9}$ & $-0.29(-0.14$ to 0.73$)$ \\
\hline Change & $+2.15 \pm 4.74$ & $+1.82 \pm 2.31$ & 0.38 & 0.698 & $-0.08(-0.35$ to 0.52$)$ \\
\hline \multicolumn{6}{|c|}{ Emotional burden } \\
\hline Baseline & $6.10 \pm 5.54$ & $6.55 \pm 4.78$ & -0.38 & 0.698 & - \\
\hline After 6 weeks & $6.37 \pm 2.30$ & $10.32 \pm 3.52$ & -5.93 & $<0.001$ & $-1.32(-1.81$ to -0.84$)$ \\
\hline Change & $+0.27 \pm 5.18$ & $+3.77 \pm 3.72$ & -3.46 & $0.001^{9}$ & $-0.77(-1.23$ to -0.32$)$ \\
\hline \multicolumn{6}{|l|}{ Overall } \\
\hline Baseline & $31.87 \pm 21.45$ & $25.67 \pm 14.97$ & 1.50 & 0.138 & - \\
\hline After 6 weeks & $33.55 \pm 5.54$ & $43.12 \pm 10.51$ & -5.1 & $<0.001$ & $-1.14(-1.61$ to 0.67$)$ \\
\hline Change & $+1.67 \pm 19.23$ & $+17.45 \pm 9.83$ & 4.61 & $<0.001^{9}$ & $-1.02(-1.49$ to -0.56$)$ \\
\hline
\end{tabular}

$C B I=$ Caregiver Burden Inventory; $S D=$ standard deviation; $d f=$ degrees offreedom; $C I=$ confidence interval.

*Self-assessed using a Persian version of the 24-item CBI tool. ${ }^{13,15}{ }^{\dagger}$ The control group received normal care, whereas the intervention group received additional education sessions at baseline, prior to surgery, the day after surgery and before discharge. ${ }^{\neq}$Total sum scores for each dimension ranged from 0-20, except for physical burden which ranged from 0-16, with higher scores indicating greater caregiver burden. ${ }^{13}{ }^{\$}$ Degrees of freedom $=78$. Statistically significant at $P<0.050$

$P=0.003)$ and emotional burden $(6.37 \pm 2.30$ versus $10.32 \pm 3.52 ; P<0.001)$, but not evolution $(6.80 \pm 1.91$ versus $7.80 \pm 2.98 ; P=0.199)$.

Similarly, significant differences in pre-post mean CBI score changes from baseline were noted for all dimensions, except for social burden. The effect size of the educational programme was high for all dimensions apart from social burden. The relationship between caregiver burden and the patients' ability to independently perform tasks was found to be non- significant using Pearson's correlation coefficient. Therefore, patient ability was not considered a confounding variable.

\section{Discussion}

Family caregivers often experience a great deal of physical and emotional distress and require additional support to alleviate the burden of caregiving. ${ }^{11,18,19}$ As such, health problems not only impact the affected 
patient, but also the health and quality of life of their family members and caregivers. Previous research indicates that support and educational interventions may be effective in reducing caregiver burden and improving the physical and mental wellbeing of both the caregiver and patient. ${ }^{20-22}$ Such interventions usually focus on increasing knowledge of the disease, enabling the caregiver to adapt to the realities of caring for the patient and promoting enhanced communication and problem-solving skills. ${ }^{20,21}$

Robley et al. stressed the importance of alleviating stress among CABG patients and their family caregivers by providing accurate and honest information throughout the diagnosis and treatment process, as well as promoting empathy among nurses, arranging routine telephone communications and providing bedside education and support. ${ }^{11}$ However, most previous studies assessing the effects of educational support programmes have focused on the family caregivers of patients undergoing palliative care and those with stroke, end-stage cancer and heart failure. ${ }^{23-28}$ Moreover, there is a need to evaluate the effect of such interventions in different sociocultural settings, since sociocultural factors have been found to influence care behaviours and family relationships. ${ }^{29}$

The results of the current study showed that the implementation of an educational programme resulted in a significant reduction in caregiver burden among the family caregivers of patients undergoing CABG surgery in Iran, with a substantial effect size. Overall, significant differences in mean scores between the intervention and control groups were observed, both for overall summed CBI scores as well as mean scores for most specific dimensions of caregiver burden. These findings could be attributed to greater awareness among family caregivers in the intervention group regarding strategies for coping with and managing problems related to patient care. In addition, the educational support programme could have helped to decrease their anxiety and stress and improve their confidence. This is important as increased levels of stress among family caregivers have been found to have a direct relationship with depression and a negative relationship with self-confidence. ${ }^{30}$

Moieni et al. previously reported that a familybased nursing intervention was effective in reducing caregiver burden among the family caregivers of patients undergoing CABG surgery in Iran. ${ }^{10}$ Similarly, Etemadifar et al. found that a supportive educational group intervention was successful in reducing caregiver burden among the family caregivers of patients with heart failure in Iran. ${ }^{31}$ However, Ågren et al. indicated that a psycho-educational intervention had no effect on caregiver burden among the caregivers of patients with postoperative heart failure in Sweden..$^{32}$ These differences in findings could be related to variations in the research population and intervention protocols, particularly as the latter study was a pilot study involving a small sample. ${ }^{32}$

In the current study, the intervention and control groups demonstrated significant differences in caregiver burden in terms of time dependence and emotional burden. In particular, family caregivers who took part in the educational support programme had significantly lower mean CBI scores for these dimensions compared to those in the control group. Moreover, the effect size of the educational programme in these dimensions was medium to high. Ghane et al. previously reported that a supportive educative programme decreased caregiver burden among the family caregivers of haemodialysis patients in Iran after six weeks, although effect size was not reported..$^{33}$ Overall, the greatest caregiver burden reported by subjects in the present study was in the time dependence dimension, regardless of group allocation. Consistent with these findings, another study reported that the greatest caregiver burden among the caregivers of patients with coronary artery disease lay mainly in demands to the caregiver's personal time. ${ }^{3}$

NasrAbadi et al. found that implementation of a continuous care model led to a reduction in caregiver burden in the social dimension among the family caregivers of patients undergoing $\mathrm{CABG}$ surgery in Iran. ${ }^{34}$ This is consistent with the results of the present study. Such findings likely arise because participants receive information regarding patient management, as well as advice regarding coping with stress, thereby helping to improve their mental and emotional health and relieve their anxiety. In addition, Baptista Marques et al. found that social support was the second most used coping strategy by the family members of haemodialysis patients. ${ }^{35}$

This study was subject to certain limitations which may have affected the generalisability of the results. The study was conducted in a single centre, albeit one of the largest cardiac referral centres in Iran. Moreover, the non-randomisation of the group allocation assignments may have affected the results as there were more female caregivers in the intervention group, whereas the opposite was true for the control group. According to Chappell et al., the majority of caregivers tend to be women. ${ }^{36}$ Indeed, most family caregivers of elderly patients and those with chronic diseases in Iran are female. ${ }^{37}$ Moreover, cultural gender expectations relegate tasks associated with caring for children, patients, individuals with disabilities and older people to women as part of their household duties, along with other chores. 


\section{Conclusion}

Caring for patients can have negative effects on the physical, psychological, emotional and social health of family caregivers. The current study found that an educational support programme was successful in significantly reducing caregiver burden among the family members of patients undergoing CABG surgery in Iran. Healthcare providers are therefore encouraged to incorporate additional educational support into the routine care of $\mathrm{CABG}$ patients in order to support family caregivers.

\section{CONFLICT OF INTEREST}

The authors declare no conflicts of interest.

\section{FUNDING}

This study was funded by the Iran University of Medical Sciences.

\section{References}

1. World Health Organization. Global status report on noncommunicable diseases 2014. From: www.who.int/nmh/publica tions/ncd-status-report-2014/en/ Accessed: Jul 2020.

2. Hollis IB, Jennings DL, Oliphant CS, Baker WL, Davis EM, Allender JE, et al. Key articles and guidelines in the management of patients undergoing cardiac surgery. J Pharm Pract 2015; 28:67-85. https://doi.org/10.1177/0897190015570566.

3. Mochari-Greenberger H, Mosca M, Aggarwal B, Umann T, Mosca L. Caregiver status: A simple marker to identify patients at risk for longer post-operative length of stay, rehospitalization or death. J Cardiovasc Nurs 2014; 29:12-19. https://doi. org/10.1097/JCN.0b013e318274d19b.

4. McDonald J, McKinlay E, Keeling S, Levack W. Complex home care: Challenges arising from the blurring of boundaries between family and professional care. Kōtuitui New Zealand J Soc Sci Online 2017; 12:246-55. https://doi.org/10.1080/11770 83X.2017.1373681

5. Theobald K, McMurray A. Coronary artery bypass graft surgery: Discharge planning for successful recovery. J Adv Nurs 2004; 47:483-91. https://doi.org/10.1111/j.1365-2648.2004.03127.x.

6. Sautter JM, Tulsky JA, Johnson KS, Olsen MK, Burton-Chase AM, Lindquist $\mathrm{JH}$, et al. Caregiver experience during advanced chronic illness and last year of life. J Am Geriatr Soc 2014; 62:1082-90. https://doi.org/10.1111/jgs.12841.

7. Alzahrani SH, Fallata EO, Alabdulwahab MA, Alsafi WA, Bashawri J. Assessment of the burden on caregivers of patients with mental disorders in Jeddah, Saudi Arabia. BMC Psychiatry 2017; 17:202. https://doi.org/10.1186/s12888-017-1368-1.

8. ParkEO, Yates BC, Schumacher KL, Meza J, Kosloski K, Pullen C. Caregiving demand and difficulty in older adult spousal caregivers after coronary artery bypass surgery. Geriatr Nurs 2013; 34:383-7. https://doi.org/10.1016/j.gerinurse.2013.05.007.

9. Halm MA. Age and gender influences on the needs, concerns and strategies of CABG caregivers. Heart Lung 2017; 46:159-65. https://doi.org/10.1016/j.hrtlng.2017.01.012.

10. Moieni M, Poorpooneh Z, Pahlavanzadeh S. Investigating the effect of family-focused nursing intervention on caregiver burden of the family members of the patients undergoing coronary bypass surgery in Isfahan Shahid Chamran Hospital during 2012. Iran J Nurs Midwifery Res 2014; 19:187-92.
11. Robley L, Ballard N, Holtzman D, Cooper W. The experience of stress for open heart surgery patients and their caregivers. West J Nurs Res 2010; 32:794-813. https://doi.org/10.1177/01939459 10361469.

12. Bahrami M, Etemadifar S, Shahriari M, Farsani AK. Caregiver burden among Iranian heart failure family caregivers: A descriptive, exploratory, qualitative study. Iran J Nurs Midwifery Res 2014; 19:56-63.

13. Novak M, Guest C. Application of a multidimensional caregiver burden inventory. Gerontologist 1989; 29:798-803. https://doi. org/10.1093/geront/29.6.798

14. Katz S, Downs TD, Cash HR, Grotz RC. Progress in the development of the index of ADL. Gerontologist 1970; 10:20-30. https://doi.org/10.1093/geront/10.1_part_1.20.

15. Abbasi A, Shamsizadeh M, Asayesh H, Rahmani H, Hosseini SA, Talebi M. [The relationship between caregiver burden with coping strategies in family caregivers of cancer patients]. Iran J Psychiatr Nurs 2013; 1:62-71.

16. Khoei MA, Akbari ME, Sharifi F, Fakhrzadeh H, Larijani B. Translation and validation of the activities of daily living scale with Iranian elderly cancer patients treated in an oncology unit. Asian Pac J Cancer Prev 2013; 14:2731-7. https://doi.org/10.73 14/apjcp.2013.14.5.2731.

17. Mendes M. Is there a role for cardiac rehabilitation after coronary artery bypass grafting? There is no role for cardiac rehabilitation after coronary artery bypass grafting. Circulation 2016; 133:2538-43. https://doi.org/10.1161/CIRCULATIONAHA.115.017800.

18. Leigh ES. The role of support in the physical and psychological health of coronary artery bypass graft surgery patients and their partners. Ph.D. Thesis, 2013, University College London, UK.

19. Park B, Kim SY, Shin JY, Sanson-Fisher RW, Shin DW, Cho J, et al. Prevalence and predictors of anxiety and depression among family caregivers of cancer patients: A nationwide survey of patient-family caregiver dyads in Korea. Support Care Cancer 2013; 21:2799-807. https://doi.org/10.1007/s00520-013-1852-1.

20. Hudson P, Payne S. Family caregivers and palliative care: Current status and agenda for the future. J Palliat Med 2011; 14:864-9. https://doi.org/10.1089/jpm.2010.0413.

21. Hartmann M, Bäzner E, Wild B, Eisler I, Herzog W. Effects of interventions involving the family in the treatment of adult patients with chronic physical diseases: A meta-analysis. Psychother Psychosom 2010; 79:136-48. https://doi.org/10.1159/000286958.

22. Myaskovsky L, Posluszny DM, Schulz R, DiMartini AF, Switzer GE, DeVito Dabbs A, et al. Predictors and outcomes of health-related quality of life in caregivers of cardiothoracic transplant recipients. Am J Transplant 2012; 12:3387-97. https://doi.org/10.1111/j.16 $00-6143.2012 .04243 x$

23. Hafsteinsdóttir TB, Vergunst M, Lindeman E, Schuurmans M. Educational needs of patients with a stroke and their caregivers: A systematic review of the literature. Patient Educ Couns 2011; 85:14-25. https://doi.org/10.1016/j.pec.2010.07.046.

24. Lee KC, Yiin JJ, Chao YF. Effect of integrated caregiver support on caregiver burden for people taking care of people with cancer at the end of life: A cohort and quasi-experimental clinical trial. Int J Nurs Stud 2016; 56:17-26. https://doi.org/10.1016/j. ijnurstu.2016.01.002

25. Hu X, Dolansky MA, Su Y, Hu X, Qu M, Zhou L. Effect of a multidisciplinary supportive program for family caregivers of patients with heart failure on caregiver burden, quality of life, and depression: A randomized controlled study. Int J Nurs Stud 2016; 62:11-21. https://doi.org/10.1016/j.ijnurstu.2016.07.006.

26. Liljeroos M, Ågren S, Jaarsma T, Årestedt K, Strömberg A. Long-term effects of a dyadic psycho-educational intervention on caregiver burden and morbidity in partners of patients with heart failure: A randomized controlled trial. Qual Life Res 2017; 26:367-79. https://doi.org/10.1007/s11136-016-1400-9. 
27. Holm M, Årestedt K, Carlander I, Fürst CJ, Wengström Y, Öhlen J, et al. Short-term and long-term effects of a psycho-educational group intervention for family caregivers in palliative home care: Results from a randomized control trial. Psychooncology 2016; 25:795-802. https://doi.org/10.1002/pon.4004.

28. Azizi A, Khatiban M, Mollai Z, Mohammadi Y. [The effect of informational support on satisfaction of family caregivers of patients with hemiplegic stroke from receiving information]. Avicenna J Nurs Midwifery Care 2018; 26:211-18. https://doi. org/10.30699/sjhnmf.26.4.211.

29. Dunbar SB, Clark PC, Quinn C, Gary RA, Kaslow NJ. Family influences on heart failure self-care and outcomes. J Cardiovasc Nurs 2008; 23:258-65. https://doi.org/10.1097/01.JCN.000030 5093.20012.b8.

30. Kim D. Relationships between caregiving stress, depression, and self-esteem in family caregivers of adults with a disability. Occup Ther Int 2017; 2017:1686143. https://doi.org/10.1155/ 2017/1686143

31. Etemadifar S, Bahrami M, Shahriari M, Farsani AK. The effectiveness of a supportive educative group intervention on family caregiver burden of patients with heart failure. Iran J Nurs Midwifery Res 2014; 19:217-23.
32. Ågren S, Strömberg A, Jaarsma T, Luttik ML. Caregiving tasks and caregiver burden: Effects of an psycho-educational intervention in partners of patients with post-operative heart failure. Heart Lung 2015; 44:270-5. https://doi.org/10.1016/j.hrtlng.2015.04.003.

33. Ghane G, Farahani MA, Seyedfatemi N, Haghani H. [Effectiveness of supportive educative program on the burden in family caregivers of hemodialysis patients]. Nurs Midwifery J 2017; 14:885-95.

34. NasrAbadi T, Sharafi S, FallahTafti B, Vaezi AA, Heidari MR. [Investigating the effect of continuous care model on social health status of family caregivers in hospitalized patients undergoing coronary artery bypass graft surgery]. J Shahid Sadoughi Univ Med Sci 2016; 24:513-23.

35. Baptista Marques FR, Botelho MR, Marcon SS, Lenzi Pupulim IS, Coping strategies used by family members of individuals receiving hemodialysis. Text Context Nurs 2014; 23:915-24. https://doi.org/10.1590/0104-07072014002220011.

36. Chappell NL, Dujela C, Smith A. Caregiver well-being: Intersections of relationship and gender. Res Aging 2015; 37:623-45. https://doi.org/10.1177/0164027514549258.

37. Farahani MA, Bahloli S, JamshidiOrak R, Ghaffari F. Investigating the needs of family caregivers of older stroke patients: A longitudinal study in Iran. BMC Geriat 2020; 20:313. https://doi. org/10.1186/s12877-020-01670-0. 